\title{
Student time allocation, the learning environment and the acquisition of competencies
}

Citation for published version (APA):

Meng, C. M., \& Heijke, J. A. M. (2005). Student time allocation, the learning environment and the acquisition of competencies. Researchcentrum voor Onderwijs en Arbeidsmarkt, Faculteit der Economische Wetenschappen. ROA Research Memoranda No. 1E https://doi.org/10.26481/umaror.200501E

Document status and date:

Published: 01/01/2005

DOI:

10.26481/umaror.200501E

Document Version:

Publisher's PDF, also known as Version of record

\section{Please check the document version of this publication:}

- A submitted manuscript is the version of the article upon submission and before peer-review. There can be important differences between the submitted version and the official published version of record.

People interested in the research are advised to contact the author for the final version of the publication, or visit the DOI to the publisher's website.

- The final author version and the galley proof are versions of the publication after peer review.

- The final published version features the final layout of the paper including the volume, issue and page numbers.

Link to publication

\footnotetext{
General rights rights.

- You may freely distribute the URL identifying the publication in the public portal. please follow below link for the End User Agreement:

www.umlib.nl/taverne-license

Take down policy

If you believe that this document breaches copyright please contact us at:

repository@maastrichtuniversity.nl

providing details and we will investigate your claim.
}

Copyright and moral rights for the publications made accessible in the public portal are retained by the authors and/or other copyright owners and it is a condition of accessing publications that users recognise and abide by the legal requirements associated with these

- Users may download and print one copy of any publication from the public portal for the purpose of private study or research.

- You may not further distribute the material or use it for any profit-making activity or commercial gain

If the publication is distributed under the terms of Article $25 \mathrm{fa}$ of the Dutch Copyright Act, indicated by the "Taverne" license above, 


\title{
Student time allocation, the learning environment
} and the acquisition of competencies

\author{
ROA-RM-2005/1E
}

Christoph Meng, Hans Heijke

Research Centre for Education and the Labour Market

Faculty of Economics and Business Administration

Maastricht University

Maastricht, January 2005 
ISBN 90-5321-405-4

Sec05.007 


\section{Contents}

Page

Abstract $\quad$ i

Acknowledgments $\quad$ i

1 Introduction 1

2 Competencies transformation at Higher Education 3

2.1 The production process 3

2.2 Learning environment 5

2.3 A simple theoretical approach $\quad 8$

3 Data and a first descriptive view 12

3.1 Discipline-specific and generic competencies 12

$\begin{array}{ll}3.2 \text { Learning environment } & 13\end{array}$

$\begin{array}{ll}3.3 \text { Student time allocation } & 15\end{array}$

4 Empirical analyses $\quad 18$

4.1 The stochastic frontier model 18

4.2 Results: The acquisition of generic and discipline-specific competencies 21

5 Conclusion 29

$\begin{array}{ll}\text { References } & 32\end{array}$

$\begin{array}{ll}\text { Appendices } & 35\end{array}$ 



\begin{abstract}
This paper investigates the significance of the higher education learning environment and the student's time allocation over study related activities for the acquisition of generic and discipline-specific competencies. We discern four learning environments according to the emphasis placed on activating learning methods and the emphasis placed on the teacher as main source of information. Time used is measured for attention of formal education, selfstudy, extra-curricula activities and paid work. Using a unique data set on European higher education graduates, providing detailed information, we investigate the competencies acquisitions process by stochastic frontier production function methods.

The results suggest that activating learning methods are effective in both, the acquisition of generic competencies and the acquisition of discipline-specific competencies. Moreover, the results show that discipline-specific competencies are acquired by attending formal education, by self-study and by paid work, as long as there is a strong link between the work and the study. Generic competencies are acquired by self-study and paid work that is related to the study.
\end{abstract}

\title{
Acknowledgments
}

We would like to thank Lex Borghans, Andries de Grip, Jeannette Hommes, Ben Kriechel, Karl Ulrich Mayer, Joan Muysken, Rolf van der Velden, Cees van der Vleuten, the conference participants at TIY (2004, Nuremberg) and the participants at two Maastricht University seminar (2004) for comments and discussions on earlier drafts of this paper. 



\section{Introduction}

Successful labor market performance of higher education graduates is generally associated with the acquisition of the correct knowledge and competencies. High quality education in a particular discipline is still seen as important for preparing graduates for a high level of performance on entry into the labor market, where advanced and often strongly specialized knowledge is required. However, higher education has to consider the increased expectations of firms to meet a graduate resembling an 'active agent'. This active agent not only addresses problems in a creative manner but is able to expand and adapt the potentialities of an existing job. He looks further than the narrow boarders of his task and understands what is needed for a good functioning of the organization he is part of. Moreover, in a world wherein subject knowledge is rendered obsolete with an increasing rapidity by the pace of technological progress (Teichler, 1999), the active agent is expected to be prepared for lifelong learning. In line with that, Albeda (1998) argues that learning is no more the privilege of the young or the monopoly of schools and that life-long learning and permanent education are clear necessities for any type of career. Hence, higher education is confronted with an increasing demand for graduates with a high level of generic competencies.

Given that time, manpower and capital used in higher education is limited available, the tension between the need for a high level of discipline-specific competencies and at the same time the need for a high level of generic competencies may force to make a trade-off with respect to the curriculum setup in higher education. Shall higher education provide courses aimed at the preparation of graduates for a particular but narrow type of occupation or rather courses to prepare graduates as active, flexible and well-rounded academic professionals? Like a pendulum, opinions have been changing between advancing one of the two extremes ${ }^{1}$, with recently swinging more strongly away from the narrow education of discipline-specific competencies to an increased emphasis on generic competencies (see e.g. Bowden and Marton, 1998, Teichler, 1999).

The growing demand for generic competencies in the labor market, together with an upcoming criticism on traditional teaching styles, led in the last decades to a widespread establishment of activating learning methods. These activating learning methods are the visible surface of a much deeper paradigm shift that is taking place in higher education. The change we observe is the shift from a higher education institute, as a place that exists to provide instruction, to a higher education institute that exists to produce learning. In the former case, the means is the end. In the later case, the means and the end are separated and the end governs the means (Barr and Tagg, 1995). In line with that shift, the actor playing the leading character in higher education studies is changing as well. Whereas in the

1. Becker (1964) for instance concluded that the long pay-off period to education "increases the advantage of an education that is useful in many kinds of economic environments" (p. 204). Contrary to that, Rosen (1983), analyzing whether individuals should specialize or not when investing in human capital, concluded that specializing is beneficial when the cost of skills acquisition are separable. 
traditional style the central figure is the teacher who controls the learning process and delivers the knowledge in small pieces to the passive receiver, activating learning methods expect the learner (student) to be an active discoverer. By stimulating the active discoverer in the student, activating learning environments are expected to promote the acquisition of generic competencies, such as 'gathering information', 'interpersonal competencies', 'team working' or 'problem-solving abilities' (see e.g. de Corte, 1990; Everwijn, 1999; van Woerden, 1997).

Considering these newer didactic methods, the question arises if an implementation of them just trades the acquisition of discipline-specific competencies for the acquisition of generic competencies or allows to provide a win-win situation: higher education graduates are able to acquire both types of competencies on a higher level. To address this question, the students time allocation over different types of study activities, which might partially be endogenous to the didactic method used by the higher education institute ${ }^{2}$ he attends, needs to be addressed as well. As a matter of fact, earlier findings (see e.g. Romer, 1993; Durden and Ellis, 1995; Dolton et al., $2001^{3}$ ) that attending formal education is of crucial importance for the learning outcome of higher education graduates question the implementation of activating learning methods, such as problem-based learning, where lectures are mostly traded-off for more self-learning time. Considering explicitly the learning environment in combination with the student time allocation will provide us with further insight on the competencies acquisition in higher education and with crucial information on how to adapt higher education curricula to address the challenges of a knowledge oriented society.

To address these questions, we discern four learning environments according to (1) the emphasize placed on the teacher as the main source of information and (2) the emphasize placed on activating learning methods such as problem-based learning. With respect to the time allocation of the students, we distinguish between time spent on (1) formal education, (2) self-study, (3) extra-curricular activities and (4) paid work.

The results indicate that activating learning methods increase the performance of students not only with respect to the acquisition of generic competencies but as well with respect to the acquisition of discipline-specific competencies. However, for the latter effect to hold, the role of the teacher inside an activating learning environment should not be underestimated. Concerning the student time allocation, our results show that discipline-specific competencies are in particularly acquired by following formal education to the extent that attendance is required, by self-study and by paid work, as long as there is a strong link between the work and the study one follows. Generic competencies are acquired by selfstudy and paid work that is related to the study.

2. We use the term 'institute' in this paper to refer to a particular university or school (e.g. University of Maastricht). In contrast to that, we use the term 'institution' to refer to a particular type of higher education (e.g. universities or Fachhochschulen)

3. These studies are all restricted to a particular type of learning environment. 
The remainder of this paper is structured as follows. Section 2 discusses the competencies transformation process that takes place in higher education. In particular, we address the role of the learning environment and the role of the student time allocation in the acquisition of generic and discipline-specific competencies. Section 3 introduces the data used for the analyses and provides a first descriptive overview over the different types of learning environment and the student time allocation. The empirical analyses are discussed in section 4 . Finally, Section 5 concludes the paper.

\section{Competencies transformation at Higher Education}

\subsection{The production process}

From an economic point of view, education can be regarded as a production process in which a variety of inputs are used to determine a multidimensional output. The multidimensionality we address here refers to the distinction between generic and disciplinespecific competencies, as will be further defined in Section 3. Formally, we write the outcome of higher education in terms of human capital $(C)$ acquired by student $i$ as a combination of discipline-specific competencies (DS) of type $s$ (e.g. law) and of generic competencies $(G)^{4}$

$$
C_{i s}=C_{1}\left(D S_{i s}, G_{i}\right)
$$

In order to analyse the educational performance of students, we consider a general production function:

$$
C_{i s}=C_{2}(S, I, R, D, T, X)+\varepsilon
$$

where $S=$ students inputs (e.g. pre-higher education schooling achievements), $I=$ institutional/programme factors (e.g. exam formalities, nominal study time), $R=$ resources inputs (e.g. public money spent per student), $X=$ other inputs (e.g. family inputs, peer inputs but also factors outside the classroom) and $\varepsilon=$ a stochastic term. Moreover, we add explicitly the two factors set central in the later analyses, namely $D=$ didactic techniques (e.g. activating learning environment) and $T=$ student time allocation (e.g. time spent on formal education or on self-study).

4. We add no subscript $(s)$ to $G$ to index the programme wherein generic competencies are acquired, indicating that this does not matter. In other words, we use the term generic competencies not to refer to elements common to different subject-based competencies but strictly to the additional, subject independent content of these competencies useable in other fields. 
Central in this production process is the student himself. Unfortunately, students entering a higher education programme are not an empty box that can be filled with competencies. Rather, they already passed through a long formation trajectory by parents, family or, generally spoken, through their social environment and the several years of pre-higher education schooling. Hence, the stock of discipline-specific and generic competencies already settled down forms the basis on which addition and changes during the study at the higher education institute takes place. Moreover, the initial level of competencies can have a sharp impact on the effectiveness with which additional competencies are acquired. This might in particular hold with respect to generic competencies to the extent that they reflect the initial learning ability level of the student. We return to these points of concern when discussing our empirical results in Section 4. Next, student characteristics such as their motivation, learning style or locus of control influence the competencies transformation process, although it is questionable to what extent they can be seen independent of the initial competencies.

Most studies on educational performance (for an overview see Hanushek, 2002), focus on the resources available to the schooling system. More specific, they intend to measure the effects of (1) real resources of the classroom (teacher education, teacher experience, class size or teacher-student ratios), (2) financial resources (expenditure per student or teacher salary) and, (3) measures of other resources in schools (specific teacher characteristics, administrative inputs or facilities). We acknowledge the economic importance of these input factors, but believe that such studies underscore the importance of a crucial aspect of the production process: the didactic technique. In contrast to the other aspects forming the learning context, the didactic method used is at the heart of the production process ${ }^{5}$. Of equal importance for the contribution to the higher education outcome might be the student's individual time allocation over different study activities. This aspect seems in particular of interest on a higher education level, as students at this level are generally given a large amount of freedom with respect to it.

We agree that our shift in the focus to the effects of didactic techniques and student time allocation rather relocates the window in the black box than creates a new one. Still, we believe that this helps us further on the journey to understand the crucial mechanisms inside the competencies transformation process of higher education.

In what follows, we briefly address the role of the learning environment, and in particular the roles of activating learning methods, and the student time allocation. Thereafter, we present a simple theoretical framework addressing the main questions involved.

5. An important side mark is that we do not address the possible impact of a change in the learning environment on resources such as labor or infrastructure costs. As a matter of fact, activating learning methods are more labor intensive and need a large number of small rooms. To what extent an increase in financial costs will reduce possible benefits of activating learning methods presented in this paper will be an interesting line of research for the future. 


\subsection{Learning environment}

Traditionally, higher education studies are organized around lectures that intend to help the students to understand the literature. At the end of the study (course), an examination is waiting in which the students have to demonstrate their understanding of the literature's content. This traditional style of teaching has been suspect to several criticisms. Guskin (1994, cited in Barr and Tagg, 1995) argued that "The primary learning environment for undergraduate students, the fairly passive lecture-discussion format where faculty talk and most students listen, is contrary to almost every principle of optimal setting for student learning". More specific, Gerritsen (1999) argued that the traditional setting risks that students acquire knowledge that is meaningless to them and hence will soon be forgotten after the examination. Furthermore, Schmidt and Bouhuijs (1985) criticized this type of learning environment on the base that it divides the material up into distinct disciplines, whereas the reality the graduates encounter in their professional career is rather organized around problems, which have to be addressed using knowledge from a range of disciplines. These critics have in the last decades led to more and more applications of activating learning methods.

\subsubsection{Activating learning environments}

Central to all sorts of activating learning environments is their student-centred approach, requiring the student to be an active discoverer who is directly involved in the learning process rather than feed passively by the teacher. Hence, activating learning environments include didactic styles that help and motivate students to learn and that promote an active engagement of students with the subject matter, their desire to understand it and their ability to actively apply it. Main examples of activating learning environments are project-based learning and problem-based learning ${ }^{6}$. The problem-based learning approach began in medical teaching at the McMaster University in Canada. Its central characteristics is that "Problem-based learning is the learning that results from the process of working toward the understanding or solution of a problem. The problem is encountered first in the learning process" (Barrows, Tamblyn, 1980). Although problem-based learning was initiated in the 1970 s, its roots can be traced back to the beginning of the $20^{\text {th }}$ century and in particular to the work of Dewey (1916). Dewey ${ }^{7}$ proposes that 'Methods which are permanently successful in formal education ...go back to the type of situation which causes reflection out of school in ordinary life. They give pupils something to do, not something to learn; and the doing is of such a nature as to demand thinking, or the intentional noting of connections; learning naturally results" (Dewey, 1916, p.154). In line with that, and nearly 100 years later, Vaatstra and de Vries (2003) conclude on the basis of a literature review that the underlying

6. According to van Woerden (1997) there are great similarities between problem-based and project-based learning. In both types of environment, students gain concrete experience with learning independently, working together in groups (education is generally organized around small group meetings), and approaching problems systematically.

7. Dewey belonged to the progressive education movement in America. This movement had its sources in the philosophies of Jean Jacques Rousseau, Johann Pestalozzi, and Friedrich Froebel. 
theoretical point of view is that activating learning methods allow students to acquire the subject matter in an active way, resulting in a better recall of it and, because they are experienced to apply theoretical knowledge to solve cases, they are expected to be better able to apply this knowledge in practice. Moreover, by stimulating the active discoverer in the student, activating learning environments should promote the acquisition of generic competencies, such as 'gathering information', 'interpersonal competencies', 'team working' or 'problem-solving abilities' (see e.g. de Corte, 1990; Everwijn, 1999; van Woerden, 1997). Comparable ideas are presented in three recent books on learning and teaching at higher education level (Prosser and Trigwell, 1999; Biggs 2003; Ramsden, 2003). The general idea of these authors is that the teacher has to create an activating learning environment that stimulates the student to acquire knowledge in an active manner. This will enhance deep learning and a higher level of understanding.

The large majority of previous empirical research on the effectiveness of activating learning methods concentrated on the field of medicine (e.g. Dochy, Segers, van den Bossche and Gijbels, 2003; Norman and Schmidt, 2000). Furthermore, some studies focused on other disciplines, such as the study by van den Bossche, Segers, Gijbels and Dochy (2001) who investigated the effect of problem-based learning environments on the results of economic students. What all of these studies generally conclude is that students experiencing problembased learning environments are better at applying knowledge than students from a conventional learning environment. However, what is not clear is whether there are further differences in the acquired type and level of competencies between students from these two types of learning environments. Moreover by focussing the analyses on a particular field of study or even a particular higher education institute, the possibility to generalize the results is strongly restricted. Finally, these studies mostly neglect the importance of time allocated by students to formal education, self-study and other study activities and hence the possible close relation between learning environment and time allocation. A broader approach, using data on Dutch university graduates, has been carried out by Vaatstra and de Vries (2003). Vaatstra and de Vries conclude that graduates who study in an activating learning environment during their university education possess at time of graduation more general and reflective competencies than graduates who completed a more traditional type of education. On the other hand, they could not establish a relationship between the type of learning environments and the amount of discipline-specific competencies.

Concluding this section, we can state that previous research established that activating learning methods seem in particular to stimulate competencies necessary to apply the knowledge acquired in higher education and competencies related to address problems and to reflect on one's own work.

\subsubsection{Time allocation}

Compared to secondary education, students at higher education institutes possess a considerable size of freedom in their decisions how to allocate time to different activities. The 
situation that students are obliged to spend precisely scheduled time in class rooms together with a strict control of their attendance is rather the exception than the rule. ${ }^{8}$

Surprisingly, in the light of the crucial impact the time allocation of students might have on the outcome of the educational production process, research on it is scarce. Moreover, most of the studies that control for the student time do so by measuring total time devoted to the course, a variable frequently found to be insignificant. Schmidt (1983) argues that this finding can be explained by the fact that the intensity of study varies so much among students that the assumption of time homogeneity is strongly violated or that such a time variable is overly aggregated, as students not only allocate scarce time among courses and leisure but also ration time among alternative study modes within a course.

The available previous research consists in particular of case studies carried out in the United States, such as Schmidt (1983) who uses data from an experiment run in the fall of 1970 at the University of Wisconsin-Madison. The data include 216 students of the macroeconomic principles course. Using different econometrical approaches, he finds that hours of class attention are from slightly (FIML estimates) to far more (OLS estimates) productive than hours of self-study. Romer (1993), using data from three U.S. schools (the full sample size is 195 students), runs regressions of student performance on the fraction of lectures attended, both excluding and including proxies for motivation. He finds in all estimations that the effect of class attendance is positive and significant, although the inclusion of proxies for motivation reduces the magnitude sharply. Durden and Ellis (1995), using a sample of 346 students in a Principle of Economics course, find that the typical student is not adversely affected by a few absences ... but [that] excessive absenteeism is associated strongly with poor academic performance (p. 345). Similar results are also found by Devadoss and Foltz (1996) who find that motivation positively affect attendance and that attendance positively affect class performance and by Chan, Shum and Wright (1997) who find a significant positive relationship between attendance and student performance in a Tobit model and an insignificant relationship using a Heckman selection procedure to control for the students' survival process in the course. What is common to these U.S. studies is their focus on the relationship between class attention and student performance omitting the question of time allocated to self-study.

Two studies taking next to the time allocated to the attendance of classes the time allocated to self-study explicitly into account are Dolton, Marcenaro and Navarro (2001) and Bratti and Staffolani (2002). Dolton et al. (2001), analyzing a sample of 3,722 first and final year students from the University of Malaga, find that time allocated to lectures is between twice (using a stochastic production frontier approach) and four (using OLS) times as productive than time allocated to self-study. Bratti and Staffolani (2002) estimate an academic performance regression for first year undergraduate students of economics at the University

8. Even in cases such as the economic programs at Maastricht University, where students are officially required to attend up to $100 \%$ of all meetings, students have a backdoor option and can trade the attendance for an additional written assignment. 
of Ancona. They find evidence that once they control for time allocated to self-study, the positive and significant effect of lecture attendance for some courses disappears.

The scarce availability of literature addressing directly the relationship between the allocation of time and students performance itself can be seen as a rational for further empirical studies that attempt to shed more light on this aspect. Moreover, what is generally omitted in the previous research is the impact the learning environment might have on the student time allocation. In other words, studies investigating the impact of time allocation on educational outcomes without explicitly addressing the didactic teaching methods used neglect the possible endogeneity of the time allocation with respect to the learning environment.

\subsection{A simple theoretical approach}

Those responsible for higher education together with the students try to maximize the competencies outcome. Taking the assumptions that both, the study length and the monetary resources available are limited and that for both, generic and discipline-specific competencies, the marginal costs of producing them are progressively related to the intended level, the production possibility frontiers receive an outward bow shape. Graphically, production possibility frontiers indicate the maximum level of one type of competencies that can be produced in higher education for every possible level of production of the other type of competencies. We show two possible production possibility frontiers $\left(P P F_{1}\right.$ and $\left.P P F_{2}\right)$ in Figure 1. The location of $P P F_{2}$ to the right of $P P F_{1}$ indicates a higher production possibility frontier, as an equal level of generic competencies can be combined with a higher level of discipline-specific competencies and vice versa. A step from $P P F_{1}$ to $P P F_{2}$ requires an increased level of input resources available or, at a given level of inputs, the usage of a better production method, such as a more effective learning environment.

The two dotted lines $\left(A_{d s}\right.$ and $\left.A_{g}\right)$ restrict the possible outcomes to combinations with both, a minimum level of generic competencies and a minimum level of discipline-specific competencies. Programs that do not conform to these minimum standards are expected to be ended either through loosing their accreditation, and hence their official status, or by market forces. ${ }^{9}$ Secondly, the location of the dotted lines is determined by the fact that it is neither possible to acquire a high level of discipline-specific competencies without the acquisition of a minimum level of generic competencies ('without knowing how to learn, you can not learn') nor to acquire generic competencies without learning a discipline. ${ }^{10}$ These restrictions leave those responsible a limited range to place their programme on.

9. The demand of pupils for such programs will decrease as a result of continuously unsuccessfulness of the graduates in the labor market. Logically, individual students inside a programme that is on average fulfilling the minimum requirement will have to stop their study if they do not achieve the minimum levels.

10. That the acquisition of generic competencies has to be rooted in content, that is, that educational goals such as communication or problem-solving abilities necessarily must be related to communicating something or to solving some particular kinds of problems has for instances been argued by Bowden and Masters (1993). Stephenson (1992) expresses similar ideas to those of 
Figure 2.1

The competencies output of higher education programs/graduates

Discipline-specific competencies

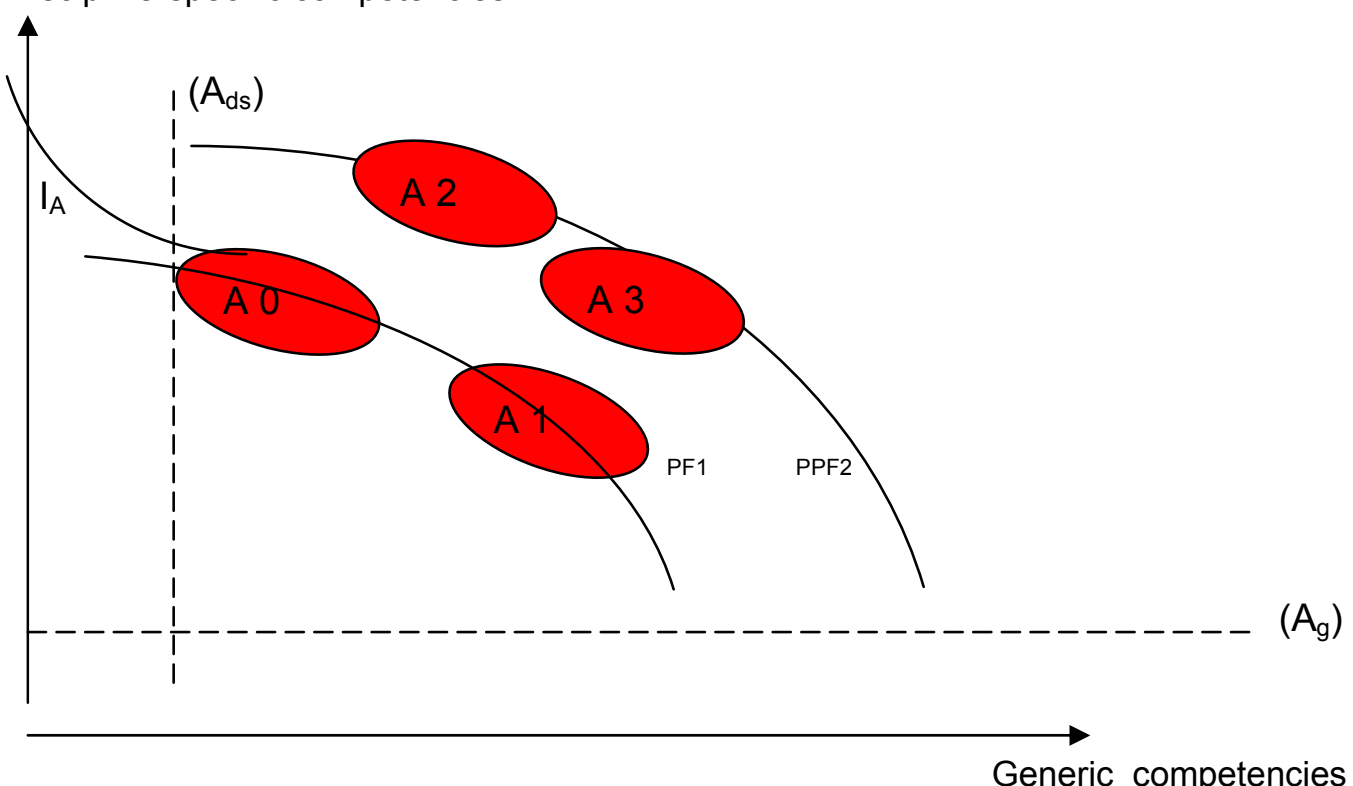

Assuming that the demand for higher education graduates consists of firms that produce their goods using generic and discipline-specific competencies, we can expect educational programs at least partially to aim at the competencies mix asked by these firms. We illustrate the demand of the firms in Figure 1 by the isoquant $I_{A}$. Graphically, an isoquant is a curvature representing different combinations of generic and discipline-specific competencies yielding the same level of output. The concave shape assumed in Figure 1 reflects the option of firms to substitute between the two competencies. However, the substitution is assumed to get more difficult, and hence expensive, the more of a particular competencies the firm intends to use. The education programme, represented by the shadowed area $A O^{11}$ is assumed to respond to the labour market demand with respect to the competencies mix an average graduate acquires. Programme $A O$, responding to a disciplinespecific competencies oriented mix asked by the production sector, directs its students at the learning of such discipline-specific competencies. The role of generic competencies is

Bowden and Masters when he suggests that the fundamental objection to a separate generic skill, which he refers to as 'bolt-on-capability', is that it denies 'the holistic nature of capability, the essential integration of personal qualities, skills and specialist knowledge which enables students to be effective' (Stephenson, 1992).

11. We draw the educational programme rather as an area than just as one point on the production frontier. By that, we indicate that the educational programme might try to achieve a particular point for the average student but that better students are able to score higher and vice versa for the less intelligent students. Moreover, the size of the area at least partially reflects the standardization within a programme with respect to the level of generic and discipline-specific competencies. The manner we draw the areas implies that focusing on a particular type of competencies goes paired with an increased level of standardization of this type of competencies. Heijke and Meng (forthcoming) show that the standardization itself is an important factor in the transition from higher education to the labor market. 
therefore rather perceived as the means by which the learning of discipline-specific competencies is enhanced than as an end itself.

Let us assume that educational programme $A 0$, using at the moment conventional teaching methods, is confronted with a shift in the labour market demand. As a consequence of changes in the manner firms operate, we assume that the competencies mix the labour market requires shifts drastically towards more value attached to generic competencies. Those responsible for educational programme $A$ now face the challenge to react. As indicated above, introducing or enforcing activating learning methods might be a possible initiative taken. But what will the outcome be? Does such a change force a trade-off between the acquisition of generic competencies and discipline-specific competencies or are these methods superior to conventional teaching methods? In the former case, introducing activating learning methods will move the output of educational programme $A 0$ along $P P F_{1}$ to (e.g.) $A 1$. In the latter case it might move outwards to for instance $P P F_{2}$. In that case, two possible outcomes achievable are $A 2$ or $A 3$. In case that the new method solely increases the level of generic competencies students possess at time of graduation, programme $A 0$ will reach A3. In case that these methods not only increase the level of generic competencies but also the level of discipline-specific competencies, our programme might find its place as $A 2$. The question what the outcome will be of such a change in the learning environment and to what extent activating learning methods help higher education programs to solve the dilemma they are in will empirically be investigated in section 4 .

Although we argued above that the time allocation of students might partially be determined by the learning environment used, we may still expect to find some heterogeneity between students inside a leaning environment with respect to time allocated to (e.g.) formal education or self-study. Considering our interest in the level and type of competencies acquired by students at time of graduation, which is a broader outcome measurement than the particular grade achieved in a course, we have to include more types of study activities than simply the time spent in lecture halls or time spent reading a book. As a matter of fact, paid working time as well as extra curricula activities might be of importance.

Let us assume that each student can convert time spent on self study $\left(\mathrm{ST}^{12}\right)$, time spent on formal education (e.g. lectures, seminars) (F), time spent on extra curricula activities (EC) and time spent on paid work (W) into additional competencies. ${ }^{13}$

(3) $C=C(F, S T, E C, W / S, I, R, D, X)$

12. We omit the subscript indicating the individual student for simplicity reasons.

13. We omit the decision of the student to enroll in higher education instead of starting to work. Furthermore, the trade-off between formal class (and/or self-study) time and time devoted to paid work during the study at a higher education institute is in this paper not regarded as a trade-off decision between study performance and money but rather as a trade-off decision between different activities influencing the competencies output. Moreover, we neglect that students might gain utility from being a 'student'. 
With $C_{F} \geq 0, C_{S T} \geq 0, C_{E C} \geq 0$ and $C_{W} \geq 0$. Furthermore, we assume diminishing returns to the time devoted to any type of activity and hence $\mathrm{C}_{\mathrm{FF}} \leq 0, \mathrm{C}_{\mathrm{STST}} \leq 0, \mathrm{C}_{\mathrm{ECEC}} \leq 0, \mathrm{C}_{\mathrm{WW}} \leq 0$. The precise relation between time devoted to a particular type of activity and the competencies outcome, as well as the degree to which diminishing returns occur, is conditional on $S$, the e.g. pre-higher education schooling achievements of the student, $I$, institutional or programme factors such as the exam formalities, $R$, resource inputs, $X$, other inputs (e.g. family inputs) and $D$, the learning environment.

This simple theoretical approach is sophisticated enough to explain why the competencies outcome of two graduates, investing the same total time in competencies acquisition, might differ based on (e.g.) a different allocation of the total time over the different manners of competencies acquisition. Figure 2 illustrates this point. Let us consider the case of an individual student attending a higher education programme at an institute that uses a conventional teaching method. For simplicity, we assume that the level of discipline-specific competencies can only be influenced by attending lectures and/or by self-study. $E_{1}$ represents the competencies transformation line of time spent in lecture halls and $E_{2}$ for time devoted to self-study. In both cases, more time allocated to the activity increases the final competencies outcome but with decreasing marginal returns. The situation in Figure 2 is drawn according to the findings of previous research we reported on (e.g. Dolton et al., 2001), namely that spending a particular amount of time on attending lectures is more effective in acquiring discipline-specific competencies than spending the same amount of time on self-study. Hence, our student can achieve a higher level of utility (reflected by a higher indifference curve $\mathrm{I}_{1}{ }^{14}$ ) by attending lectures than by spending the same amount of time on self-study $\left(I_{2}\right)$.

Figure 2.2

Transformation of time into competencies

Level of discipline-specific competencies

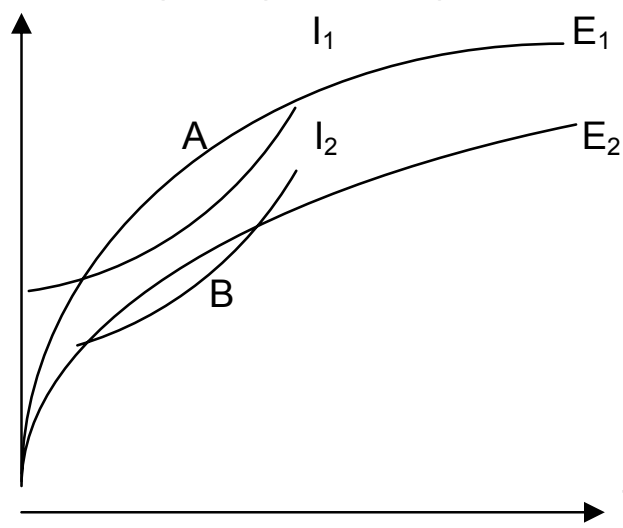

Time devoted to study activity

Note: The level of generic competencies to be acquired is set at the level possessed when entering higher education.

14. The upward sloping curvature of the indifference curve indicates the trade-off between the 'good' of acquiring competencies and the 'bad' of spending time on studying instead of having leisure time. 
However, several questions arise. How does the picture look like when we consider the acquisition of generic competencies instead of discipline-specific competencies? Might the return to formal education be related to the amount of self-study time to prepare for the class? These types of questions, together with the question of the effectiveness of learning environments addressed above will form the centre of our focus in the empirical analyses we turn to now.

\section{Data and a first descriptive view}

The research data for this paper are obtained from a European wide postal survey among 1994/1995 higher education graduates carried out in 1998. The data provide, among a whole set of personal characteristics and the competencies possessed at the time of graduation, a rich set of information with respect to the study program followed at a higher education institute. In particular, the data allow us to analyze the effects of learning environments and student time allocation for 18532 graduates in nine European countries (Austria, Finland, France, Germany, Italy, Norway, Spain, The Netherlands and United Kingdom) covering all type of higher education institutions ${ }^{15},{ }^{16}$.

In what follows, we discuss and present the operationalisation of, first, the competencies acquired by the graduates of higher education and secondly, the part of the data used to define the learning environment and the time allocation of the students.

\subsection{Discipline-specific and generic competencies}

The data contains information with respect to 36 different competencies representing different types of knowledge supply. Graduates were asked to indicate on a five-point scale, ranging from 1 ('not at all') to 5 ('to a very high extent'), the extent to which they had a given competency at time of graduation (in 1994 or 1995) Using a hierarchical clustering method, we retain two clusters of competencies representing best our idea of generic ${ }^{17}$ competencies and discipline-specific competencies ${ }^{18}$. The two clusters consist of the following individual items:

15. The data not only covers university graduates but also graduates from HBO institutes (Netherlands), Fachhochschulen (Germany), Grande Écoles (France) and University colleges (Norway).

16. Appendix A reports on the graduates per field of study and the cases per higher education institution.

17. The group of competencies we cluster under the label 'generic competencies' is as a matter of fact a subgroup of items generally labeled as generic competencies. Our approach is thereby strongly linked to the one hand the concept of 'metacognitive competencies' and on the other hand to the literature on 'critical thinking'. The former relates to the expertise about oneself as a knower, learner and actor (Weinert, 2001). The latter is according to Ennis (1991) best defined as 'reasonable reflective thinking that is focused on deciding what to believe or do'. It involves 'formulating hypotheses, alternative ways of viewing a problem, questions, possible solutions, and plans for investigating something.' Its distinction from lower-order thinking skills with their main focus on knowledge, comprehension and/or application relates back to Bloom's taxonomy of educational objectives (Bloom, 1956). Critical thinking requires prolonged education and hence their acquisition forms a centre part of higher education studies.

18. For a more detailed description of the clustering method, see Heijke, Meng and Ris (2003). 
Discipline-specific competencies

Field-specific theoretical knowledge

Field-specific knowledge of methods

\section{Generic competencies}

Learning abilities

Reflective thinking, assessing one's own work

Problem-solving abilities

Analytical competencies

Documenting ideas and information

For our analyses, we then simply calculate an average of the competency clusters possessed at time of graduation. As the individual items were measured on a five point scale from 1 ('not possessed at all') to 5 ('possessed to a very high extent') the graduates score on a cluster is also bound to between 1 and 5 .

\subsection{Learning environment}

To define the learning environment the graduate followed his or her tertiary education programme in, we rely on the respondents self-report on the emphasis attached by the higher education institute on particular curriculum aspects. More precisely, we use information on the following two questions:

"If you look back to your course of study you graduated from in 1994 or 1995: to what extent were the following modes of teaching and learning emphasized by your institution of higher education and its teachers?

A) Teacher as the main source of information and understanding?

B) Project- and problem-based learning ${ }^{19}$

For both questions, the respondents could indicate their answer on a five-point scale, ranging from 1 ('not at all') to 5 ('to a very high extent'). Based on these answers, we distinguish in particular four types of learning environments (see Matrix 1).

19. The data does not allow us to distinguish between problem based-learning and project-based learning. According to van Woerden (1997), there are great similarities between problem-based learning and project-based learning. In both types of education, students gain concrete experience with learning independently, working together in groups, and approaching problems systematically. We believe that grouping problem-based learning and project-based learning together will not jeopardize the results. 
Four different learning environments

Emphasis on problem-based learning

Weak

Strong

$\begin{array}{llcc}\text { Emphasis on teacher } & \text { Weak } & \text { Traditional (45\%) } & \text { PBL without teacher (20\%) } \\ \text { as main source of } & \text { Strong } & \text { School-class (25\%) } & \text { PBL with teacher (10\%) } \\ \text { information } & & & \end{array}$

The first two learning environments we distinguish do not use activating learning methods, at least not on a significant level (approximated by answer category 4 and 5). The third and fourth learning environments distinguished apply to a significant extent activating learning methods.

Traditional style (answer on Teacher: 1-3; answer on PBL: 1-3)

This style is characterized by the fact that the higher education institute neither puts strong or very strong emphasis on 'teacher as main source of information' nor on 'problem-based learning'. Roughly $45 \%$ of all graduates were taught according to this style.

School-class style (answer on Teacher: 4-5; answer on PBL: 1-3)

In this case, the graduates indicated that the teacher played a strong or very strong role (answer category 4 or 5 ) as central information source but that less than strong (answer category 1-3) emphasis was placed on 'problem-based learning'. This type of teaching resembles mostly the situation students are used from pre-higher education, where the teacher talks and the students listen. Considering our research population, $25 \%$ of our respondents indicated that this was the case in their higher education institute.

PBL without teacher style (answer on Teacher: 1-3; answer on PBL: 4-5)

The third style we distinguish is based on the answers of the students that 'problem-based learning' played a strong or very strong (answer category 4 or 5 ) role but that the teacher was given a less than strong (answer category 1-3) role as source of information. $20 \%$ of our respondents experienced such a learning environment. This style resembles most likely the original idea of problem- or project-based learning where the role of the teacher is seen as rather process than contents oriented.

PBL with teacher style (answer on Teacher: 4-5; answer on PBL: 4-5)

The final learning environment we discern mixes a strong or very strong (answer category 4 or 5) role of the teacher as central source of information with a strong or very strong (answer category 4 or 5) emphasis on problem-based learning. In contrast to the PBL without teacher 
style, this style gives the teacher a role beyond just process monitoring. $10 \%$ of our respondents belong to this group.

Table 3.1 reports on the usage of different learning environments in the countries and higher education institutions considered. With the exception of Germany, we see that in all countries providing two types of higher education institutions, the non-university institutions more likely provide teaching according to activating learning methods. However, in Norway, Germany and the Netherlands, the non-university institutions also score higher on the school-class learning environments.

Table 3.1

$\%$ of students in learning environment: Strata: Higher education institution

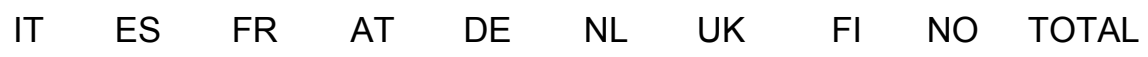

\begin{tabular}{|c|c|c|c|c|c|c|c|c|c|c|}
\hline \multicolumn{11}{|l|}{ sity type of } \\
\hline Traditional & 52 & 41 & 57 & 55 & 64 & 61 & 37 & 42 & 57 & \\
\hline School-class & 32 & 37 & 18 & 26 & 17 & 19 & 18 & 33 & 17 & \\
\hline PBL with teacher & 7 & 10 & 10 & 7 & 4 & 5 & 14 & 5 & 6 & \\
\hline PBL without teacher & 9 & 12 & 15 & 13 & 15 & 16 & 31 & 21 & 20 & \\
\hline Total & 100 & 100 & 100 & 100 & 100 & 100 & 100 & 100 & 100 & \\
\hline
\end{tabular}

Other type of higher education

Traditional

$\begin{array}{rrrrrr}23 & 41 & 43 & 28 & 25 & 33 \\ 6 & 36 & 26 & 14 & 21 & 22 \\ 25 & 9 & 13 & 17 & 20 & 16 \\ 47 & 14 & 18 & 41 & 34 & 29 \\ 100 & 100 & 100 & 100 & 100 & 100\end{array}$

PBL with teacher

PBL without teacher

$100 \quad 100 \quad 100$

100

Note: Empty cells mean not available in the sense that this institution is not available. Other type of higher education is in France the Grande Écoles, in Germany the Fachhochschulen, in the Netherlands the HBO schools, in the United Kingdom the 'new universities ${ }^{20}$, and in Norway the 'state colleges'.

Overall, the four learning environments are in all countries and higher education institutions available on a comparable pattern.

\subsection{Student time allocation}

The information on the student time allocation is based on the question: 'During your study at the higher education institute approximately how many hours a week did you during term time spend on the following activities'. The activities distinguished where 'attending formal education of the main subject', 'self-study on the main subject', 'following a second subject',

20. The reason we treat the new universities (the former polytechniques) in the United Kingdom separate from the old universities is based on their striking differences in entrance requirements and status as measured for instances by the Sunday Times League Tables (Sunday Times, 2003). Moreover, our students started their study before the 1992 Higher Education Act was implemented in the United Kingdom. 
'extra curricular activities (e.g. student association)' and 'employment'. Table 3.2 reports on the average weekly time allocation. The findings show that on average students are roughly 32 hours a week occupied with their main study. Following a second study is rather the exception than the rule, as can be seen by the fact that our average student spends just about 1 hour and 30 minutes per week on this activity which is only one third of the time he spends on extra curricular activities, such as working for a student organization. Finally, roughly 2 days a week students spend time on paid work.

Table 3.2

Student time allocation

Average weekly time ( $h$ and $\min$ )

Attending formal education of main subject

Self-study for main subject

Study time of second subject

Extra curricular activities

Employment
17 h 35 min

$14 \mathrm{~h} 49 \mathrm{~min}$

$1 \mathrm{~h} 35 \mathrm{~min}$

$4 \mathrm{~h} 47 \mathrm{~min}$

$16 \mathrm{~h} 20 \mathrm{~min}$

Dolton et al. (2001) address the difficulty to get respondents to correctly remember their time allocation. They refer to Juster and Stafford (1991) who suggested that the best way to do it is asking people to keep a diary ${ }^{21}$. However, Juster and Stafford (1999) also mention that the mistake is reduced if respondents are asked to indicate 'daily work patterns'. To the extent that the weekly time allocation will not fluctuate sharply, we use this argument as some reassurance for our approach. Furthermore, strong support comes actually from the data itself. Less than $1 \%$ of all respondents reports a total weekly time that requires the student to spend 16 hours or more on these activities per weekday. Excluding extra-curricular activities, activities student rather count as leisure time than as study or work time, the percentage of graduates reporting weekly time in line with a workload of 12 or more hours a weekday drops below $1 \%$.

Table 3.3 reports on the weekly time allocation of students separate for the nine countries considered and where available for the different higher education institutions. Students following their higher education study at a Grande Écoles institute in France spend on average more than 29 hours in the classroom, which is nearly three times more than their colleagues at Austrian universities (average of 11 hours and 41 minutes). Although Austrian students compensate it by allocating roughly seven hours more to self-study than the students at Grande Écoles do, the large number of class attention hours of the French students leads in particular to a strong reduction in hours spent on paid work. Students in the United Kingdom and the two Scandinavian countries allocate the highest number of hours

21. Dolton et al (2001) mention that also this approach is critical to a possible bias. They refer thereby to Mulligan, Schneider and Wolfe (2000) who suggest that time budget studies using diaries are subject to sampling biases as participating in such projects does not take place randomly. 
(between 21 and 23 hours) to paid work, whereas students in Spain allocate on average only three and a half hours to paid work. Considering extra curricular activities, Italian and Dutch HBO students spend with seven hours a week most time on these activities. Finally, Finnish students use significantly more time on studying for a second subject then their colleagues in other countries.

Table 3.3

Time allocation: Strata: Higher education institution

\begin{tabular}{lllllllllll}
\hline IT & ES & FR & AT & DE & NL & UK & FI & NO \\
\hline
\end{tabular}

University type of higher education

Attending lectures of

main subject

17h50m 20h05m 20h40m 11h41m 20h00m 12h30m 16h00m 12h00m 13h00m

Self -study for main

subject

Study time of second

subject

24h30m 16h59m 12h08m 17h05m 12h29m 14h35m 13h2m 12h29m 21h40m

Extra curricular activities

00h00m 02h20m 00h49m 01h45m 01h31m 03h30m 01h7m 0515m 00h21m

Employment

07h00m 04h19m 03h $37 \mathrm{~m} \quad 05 \mathrm{~h} 50 \mathrm{~m} \quad 05 \mathrm{~h} 22 \mathrm{~m} \quad 03 \mathrm{~h} 58 \mathrm{~m} \quad 05 \mathrm{~h} 15 \mathrm{~m} \quad 02 \mathrm{~h} 03 \mathrm{~m} \quad 04 \mathrm{~h} 40 \mathrm{~m}$

0h49m 03h30m 16h37m 16h20m 15h24m 14h14m 22h24m 21h07m 21h56m

Other type of higher education

Attending lectures of

main subject

Self -study for main

subject

Study time of second

subject

Extra curricular activities

Employment

$29 \mathrm{~h} 10 \mathrm{~m}$

$20 \mathrm{~h} 36 \mathrm{~m} \quad 18 \mathrm{~h} 00 \mathrm{~m} \quad 17 \mathrm{~h} 00 \mathrm{~m}$

$20 \mathrm{~h} 20 \mathrm{~m}$

$10 \mathrm{~h} 23 \mathrm{~m}$

$11 \mathrm{~h} 33 \mathrm{~m} \quad 12 \mathrm{~h} 15 \mathrm{~m} \quad 15 \mathrm{~h} 03 \mathrm{~m}$

09h02m

$00 \mathrm{~h} 35 \mathrm{~m}$

00h21m 03h $30 \mathrm{~m} \mathrm{01h03m}$

04h18m 05h15m 07h00m 06h33m 03h51m

00h07m

07h42m 18h01m 13h18m 21h53m 22h32m

Note: Other type of higher education is in France the Grande Écoles, in Germany the Fachhochschulen, in the Netherlands the HBO schools, in the United Kingdom the 'new universities' and in Norway the 'state colleges'.

When discussing the educational production process in Section 2, we argued that the time allocation might be influenced by the learning environment the study takes place in. Table 3.4 presents the weekly time schedule of our European graduates according to the learning environment the study takes place in.

Table 3.4

Time allocation: Strata: learning environment

Traditional School class

PBL with

teacher
PBL without

teacher

$\begin{array}{lllll}\text { Attending formal education of main subject } & 16 \mathrm{~h} 20 \mathrm{~m} & 18 \mathrm{~h} 20 \mathrm{~m} & 20 \mathrm{~h} 40 \mathrm{~m} & 18 \mathrm{~h} 05 \mathrm{~m} \\ \text { Self-study for main subject } & 15 \mathrm{~h} 17 \mathrm{~m} & 14 \mathrm{~h} 28 \mathrm{~m} & 13 \mathrm{~h} 46 \mathrm{~m} & 14 \mathrm{~h} 35 \mathrm{~m} \\ \text { Study time of second subject } & 01 \mathrm{~h} 45 \mathrm{~m} & 01 \mathrm{~h} 59 \mathrm{~m} & 01 \mathrm{~h} 38 \mathrm{~m} & 01 \mathrm{~h} 45 \mathrm{~m} \\ \text { Extra curricula activities } & 04 \mathrm{~h} 54 \mathrm{~m} & 04 \mathrm{~h} 40 \mathrm{~m} & 04 \mathrm{~h} 54 \mathrm{~m} & 04 \mathrm{~h} 54 \mathrm{~m} \\ \text { Employment } & 16 \mathrm{~h} 16 \mathrm{~m} & 15 \mathrm{~h} 24 \mathrm{~m} & 15 \mathrm{~h} 59 \mathrm{~m} & 17 \mathrm{~h} 58 \mathrm{~m}\end{array}$


Students taught according to the 'problem-based learning with teacher' manner spend on average 20 hours and 40 minutes in the classroom, which is roughly 2 hours more than their colleagues in a 'school-class' or 'problem-based without teacher' learning environment do and more than 4 hours more than students in a 'traditional' learning environment. Partially, the increased attendance is traded-off against a reduced allocation of time to self-study.

\section{Empirical analyses}

The objective of this paper is to relate information with respect to the learning environment the study takes place in and the time allocation of the student over different study activities to the outcome of the production process, namely the level of generic and discipline-specific competencies. In this section, we first address the empirical method used for the analyses and secondly, discuss the results.

\subsection{The stochastic frontier model}

In the previous sections, we addressed the choice of the higher education institute to apply a certain learning environment and the choice of students in allocating their time over the different possible activities to a firm that tries to obtain a particular output by the usage of different input materials. If $y=f(x)$ defines such a relationship between inputs, $x$, and the maximal potential output, $y$, then the textbook proposition that a production function is a theoretical ideal implies that the observed value of $y$ has by definition to be smaller than or equal to $f(x)$. For an empirical estimation model, this implies that in a formulation such as $y=$ $f(x \mid \beta)+\mu$, with $\mu$ representing the error term, $\mu$ has to be negative and should be interpreted as inefficiency (see e.g. Greene, 2000). The stochastic production frontier function that allows to address this problem was independently proposed by Aigner, Lovell and Schmidt (1977) and Meeusen and van den Broeck (1977). The original specifications involved a production function which had an error term with two components, one to account for random effects and another to account for technical inefficiency. Formally, such a model can be written as:

$$
y_{i}=x_{i} \beta+v_{i}-\mu_{i}
$$

with $y_{i}$, the output of the $\mathrm{i}$-th student, $x_{i}$ a vector of input quantities, $\beta$, a vector of unknown parameters, $v_{i}$, a random variable assumed to be iid. $N\left(0, \sigma_{v}{ }^{2}\right)$ that is independent of $\mu_{i}$, a non-negative random variable accounting for technical inefficiency. The model is a generalization of the standard regression model with $\mu_{i}$ as the distinguishing feature.

The underlying idea of the model is that the student's attainment on generic and disciplinespecific competencies is affected by two types of random factors, which are unobservable for us. The first type $\left(v_{i}\right)$ has a normal distribution. Dolton et al. (2001) name the assignment 
to an inspiring teacher, being a member of a good mutual or self help study group and the finding of the ideal textbook to study from, as examples for this type of random factor.

The second type of random factor $\left(\mu_{i}\right)$ relates to the inherent ability that restricts the student's achievement potential. Even when the student, and the higher education institute he attends, uses the most effective mix of ingredients, the achieved output will be less than the maximum potential output, unless the student possesses the highest innate ability allowing him the most efficient conversion of input factors into the desired output ${ }^{22}$. With respect to this second type of random factor, it might be appropriate to expect it to have an asymmetric distribution. As a matter of fact, as students entering higher education belong to the top $30-40 \%$ of the population of pupils leaving secondary education, the asymmetric distribution within higher education can be related to the admission and selection requirements inherent to higher education. Aigner, Lovell and Schmidt (1977) suggested two possible distributions, namely the absolute value of a normally distributed variable ('the socalled half-normal model) and an exponentially distributed variable. However, Battese and Coelli (1998) indicated that the half-normal specification is the most useful formulation for the kind of data we consider. ${ }^{23}$

Two final problems have to be addressed. First of all, we have to consider the heterogeneity of the graduate's level of competencies that is related to unobserved factors, such as higher education institutions, institutes or programs selection and entry standards, assessment methods or the resources available to them. In case such factors differ significantly between educational programs, higher education institutions or countries, the level of competencies indicated by student $A$ in programme 1 can not directly be compared to the level of competencies indicated by student B in programme 2 . Moreover, we have to consider that the level of competencies reported by the graduate may be related to the amount of selfcriticism and hence to the cultural dimensions of a country. To consider that these aspects imply that a particular score may be strongly biased by the educational programme, the higher education institution or the country the respondent graduated in, we use normalized scores as the dependent variables. ${ }^{24,25}$ In total, we distinguish between 98 different

22. The frontier in the model is actually set by the most able student/institute mix converting the input factors most effectively into the desired output.

23. Estimating the model assuming an exponentially distributed variable does not change the findings we present in the next section significantly.

24. A first best approach would be to distinguish between different institutes (e.g. University of Maastricht) of the higher education institution and narrow defined study programs (e.g. econometrics). Unfortunately, the data does not allow us to follow such a first best approach and forces us to use a second best approach. We aggregate therefore over institutes in a particular higher education institution (e.g. University type higher education in the Netherlands) and over narrow defined study programs. For the latter, we make use of the information on the individuals' educational field provided by the International Standard Classification of Education (ISCED, 3 digits. We recode the 3 digits ISCED into 7 education fields, namely 'arts and humanities', 'social sciences', 'business', 'law', 'natural sciences', 'engineering' and 'health'.

25. Logically, we are unable to control for the problem that graduates from a particular learning environment exaggerate with respect to their knowledge. However, we tested this by analyzing the acquisition of 'foreign language skills'. A priori, one would not expect to find differences 
educational programs nested in 14 different higher education institutions that are nested in 9 different countries. Formally, we write

$$
G_{i, \text { normalised }}=\left(G_{i}-G_{s h c}\right) / G_{\text {shc }}^{\text {st.dev. }}
$$

with $G_{i}$ the student's individual level of generic competencies, $G_{s h c}$, the average level of generic competencies in study programme $s$ in the higher education institution $h$ of the country $c$ and $G_{s h c}^{s t . d e v}$, the standard deviation of generic competencies within study programme $s$ in institution $h$ and country $c$ and, similarly,

$$
D S_{i, \text { normalised }}=\left(D S_{i}-D S_{s h c}\right) / D S_{s h c}^{s t . d e v}
$$

with $D S_{i}$ the student's individual level of discipline-specific competencies, $D S_{s h c}$, the average level of discipline-specific competencies in study programme $s$ in the higher education institution $h$ of the country $c$ and $D S_{s h c}^{\text {st.dev. }}$, the standard deviation of disciplinespecific competencies within study programme $s$ in institution $h$ and country $c$.

Hence, we do not only normalize regarding the average score of the students direct peers but also take the standard deviation and thereby the distribution into account. By doing that, we assume that scoring above (below) average indicates something different inside an educational programme where the final outcome is more strongly varying than in an educational programme with a strongly harmonized outcome.

The second problem we have to address relates to the fact that the acquisition of one type of competencies might not take place independent of the other type of competencies. This holds in particular for the acquisition of discipline-specific competencies. The manner we defined generic competencies, as a group of competencies providing a strong base for learning, indicates that they will help increasing the effectiveness with which disciplinespecific competencies are learned. In other words, the level of generic competencies students acquire might be a significant explanatory variable of the discipline-specific competencies level they acquire. For that reason, we control in the discipline-specific competencies model for the acquisition of generic competencies.

between the four learning environments discerned in this paper. The results (data not shown in this paper) confirm that. However, the analysis reveals several intuitive results indicating that it is not pure luck that there is no difference between graduates from different learning environments. In particular, the analysis shows that female graduates possess higher foreign language skills and that this holds also for graduates with a academic secondary schooling background. Furthermore, when not normalizing the output variable, graduates from Spain, Italy, France, and in particular graduates from the United Kingdom show a significant lower level of foreign language skills than the average. 
To summarize, the model we estimate in the following section consists of the following two equations:

$$
\begin{aligned}
& G_{i n}=\alpha_{g}+X_{i} \beta_{g}+Y_{i} \delta_{g}+W_{i} \chi_{g}+Z \gamma_{g}+v_{i g}-\mu_{i g} \\
& D S_{i n}=\alpha_{d s}+X_{i} \beta_{d s}+W_{i} \chi_{d s}+Z_{i} \gamma_{d s}+\hat{G}_{i n} \zeta+v_{i d s}-\mu_{i d s}
\end{aligned}
$$

with $G_{\text {in }}$ and $D S_{\text {in }}$ the normalized score of generic respectively discipline-specific competencies possessed by graduate $\mathrm{i}$ at time of graduation, $\alpha$, a constant, $X_{i}$ a vector that comprises of factors characterizing the students pre-higher education school career and personal characteristics of the student, $Y_{i}$, an additional vector of pre-higher education and personal characteristics of the student assumed only to influence the level of generic competencies, $W_{i}$, a vector that indicates the learning environment the student followed his study in, $Z_{i}$, a factor of variables indicating the students time allocation', $v_{i}$, a random variable assumed to be iid. $\mathrm{N}\left(0, \sigma_{v}{ }^{2}\right)$ that is independent of $\mu_{i}$, a non-negative random variable assumed to be a half-normal distributed variable. Moreover, we add in (8) the predicted normalized level of generic competencies as explanatory factor, $G_{\text {in }}$.

\subsection{Results: The acquisition of generic and discipline-specific competencies}

We start off by discussing the results with respect to the level of generic competencies. ${ }^{26,27}$ Table 4.1 presents the results of five models. Model $0^{28}$ includes variables reflecting personal characteristics (dummy for having higher educated parents, dummy for being male and age) and variables approximating the student's pre-higher education schooling career (dummy for academic secondary school and dummies indicating the grades with which students passed secondary school). Model $1 \mathrm{a}$ adds to these variables dummies for the learning environment and Model $1 \mathrm{~b}$ adds the time allocation variables plus information on possible internships/work placements during the study and on time periods spent abroad. With respect to the variables representing the time allocation, we add two interaction terms. First, we add an interaction ('required formal education') between the hours spent in formal

26. Appendix B defines the variables used.

27. We only report on results based on our total research population. An interesting distinction would be to discern between results of university graduates and graduates from strongly occupation oriented higher vocational education institutions (e.g. Fachhochschulen in Germany, Higher vocational education institutes in the Netherlands and university colleges in Norway). Appendix $C$ reports briefly on analyses for these two types of higher education. Generally spoken, we see that the results with respect to the learning environment we present in the main text are strongly comparable with the results for either university graduates only or higher vocational education graduates only. However, the fact that higher vocational graduates generally possess to a lower extent the possibility to allocate their time freely yields a lower significance for some time allocation variables of this group.

28. All models further include dummies for countries, higher education institutions and educational programs. 
education and a dummy that is 1 in case the higher education institute put a lot of emphasis on the attendance requirement of students. The second variable ('study related work') is an interaction between the hours allocated to paid work and a dummy that is 1 if the employment was to a high or very high extent related to the field of study. ${ }^{29}$ Whereas the former interaction variable allows controlling for if formal education hours are more effective when they are required, the latter one allows us to distinguish the impact of work related to the study from work not related to the study. Thereafter, Model 2 adds the variables on the learning environment and on the study time allocation jointly. Finally, in Model 3, we control for additional curriculum aspects. To the extent that some of these curriculum aspects may more often apply to one of the four learning environments, we can expect them to take over some of the differences explained by learning environments.

Considering the personal characteristics, we find that female students and more mature students seem to perform better (see Table 4.1). The impact of the age of the student might be related to the fact that these students spent some time between secondary school and higher education on activities (e.g. foreign experience) that more likely broaden ones horizon than focus on the topic one intends to study later on. Moreover, we find in Model 0 and Model 1a that students with higher educated parents perform better, implying that some kind of knowledge transfer between generations takes place. ${ }^{30}$ Considering the pre-higher education schooling, the results indicate that students with an academic secondary education perform better with respect to generic competencies. To the extent that academic secondary education teaches more generic competencies than vocational secondary education, this result might also simply indicate that these students start with a higher generic competencies level at their higher education study. Finally, we find that the secondary education grades are strongly positive related to the final outcome of higher education. Our findings considering the personal and pre-higher education characteristics will be later on very helpful to instrument the level of generic competencies in the empirical analyses of the discipline-specific competencies.

Entering in Model 1a the dummies indicating the type of learning environment the study took place in, the results show the superiority of learning environments including some type of activating learning methods. In Model 1a, the most effective learning environment is the 'PBL with teacher style'. However, its effect in relation to the 'PBL without teacher style' is lost in Model 2 (at least on a reasonable significance level) and Model 3.

29. We hereby base us on the following question in the survey: 'to what extent did your working experience tie up with the content of your study'. Respondents were given an answer scale from 1 (not at all) to 5 (to a very high extent). We combined answer category 4 (high extent) and answer category 5 (very high extent) to measure a strong relation between study and work.

30. To what extent such a transfer is genetically or just the fact that higher educated parents are more likely able to help their children by instructing them how to learn or how to address a problem is clearly beyond the scope of this paper. 
Table 4.1

The impact on generic competencies

Model $0 \quad$ Model 1a Model 1b Model $2 \quad$ Model 3

Constant

$\begin{array}{ccccc}0.264^{* * *} & 0.539^{* * *} & 0.113 & 0.400^{* * *} & -0.210^{* *} \\ & & & & \\ & & & & \\ 0.033^{* *} & 0.032^{* *} & 0.023 & 0.023 & 0.023 \\ -0.080^{* * *} & -0.081^{* * *} & -0.078^{* * *} & -0.080^{* * *} & -0.070^{* * *} \\ 0.010^{* * *} & 0.010^{* * *} & 0.010^{* * *} & 0.010^{* * *} & 0.008^{* * *} \\ 0.094^{* * *} & 0.108^{* * *} & 0.093^{* * *} & 0.106^{* * *} & 0.112^{* * *} \\ \text { Ref. } & \text { Ref. } & \text { Ref. } & \text { Ref. }^{* *} & \text { Ref. } \\ 0.098^{* * *} & 0.100^{* * *} & 0.091^{* * *} & 0.094^{* * *} & 0.088^{* * *} \\ 0.272^{* * *} & 0.276^{* * *} & 0.248^{* * *} & 0.255^{* * *} & 0.245^{* * *}\end{array}$

Personal and pre-higher education characteristics

Higher educated parents

Gender: man

Age

Academic pre-education

Low secondary grades

Medium secondary grades

High secondary grades

Learning environment

PBL without teacher

Traditional

School-class

PBL with teacher

Ref.

$-0.331^{* * *}$
$-0.330^{* * *}$
$0.056^{\text {** }}$

Time allocation

Formal education

Required formal education

Self-study

Study of second subject

Extra-curricula

Work

Study related work

Other time allocation

Short internship

Long internship

Time spent abroad

Additional curriculum aspects

Facts and practical knowledge

Theories and concepts

Attitudes and interpersonal skills

Independent learning

Freedom to choose courses

Direct acquisition of work experience

Out of class communication with other

students

Writing a thesis

Regular detailed assessment

$\Sigma$

$\sigma_{\mathrm{u}}$

$\sigma_{\mathrm{v}}$

$\Lambda$

$-\log L$

$\mathrm{N}$-cases

Note 1: All models further include dummies for the nine countries, dummies for the different higher education institutions inside a country and dummies for seven educational programs. Note 2: ${ }^{* * *}$ significant at a $1 \%$ level, ${ }^{* *}$ significant at a $5 \%$ level, ${ }^{*}$ significant at a $10 \%$ level.

$$
\begin{array}{lll}
-0.002^{* *} & -0.002^{* *} & -0.002^{*} \\
0.003^{* * *} & 0.002^{* *} & 0.001 \\
0.006^{* * *} & 0.006^{* * *} & 0.004^{* * *} \\
0.007^{* * *} & 0.006^{* * *} & 0.005^{* * *} \\
0.001 & 0.001 & 0.001 \\
-0.001^{*} & -0.001 & -0.001 \\
0.004^{* * *} & 0.003^{* * *} & 0.002^{* * *} \\
& & \\
& & \\
-0.021 & -0.028 & -0.036 \\
0.004 & -0.013 & -0.030 \\
0.057^{* * *} & 0.057^{* * *} & 0.063^{* * *}
\end{array}
$$$$
0.142^{* * *}
$$$$
0.177^{* * *}
$$$$
0.128^{* * *}
$$$$
0.248^{* * *}
$$$$
0.088^{\star * *}
$$$$
0.033
$$$$
0.106^{* * *}
$$$$
0.122^{* * *}
$$$$
0.145^{\star * *}
$$

$\begin{array}{lllll}1.27 & 1.25 & 1.26 & 1.25 & 1.20 \\ 0.96 & 0.95 & 0.92 & 0.90 & 0.89\end{array}$

$\begin{array}{lllll}0.82 & 0.82 & 0.82 & 0.81 & 0.81\end{array}$

$1.17^{* * *} \quad 1.16^{* * *} \quad 1.26^{* * *} \quad 1.17^{* * *} \quad 1.09^{* * *}$

$\begin{array}{lllll}26395 & 26178 & 26324 & 26115 & 25677\end{array}$

$\begin{array}{lllll}18532 & 18532 & 18532 & 18532 & 18532\end{array}$


In Model $1 \mathrm{~b}$ we replace the dummies for the learning environment by the time allocated to different study activities. Our first finding is that formal education (at least when not required) is actually reducing the effectiveness with which generic competencies are acquired. Hence, generic competencies seem not to be acquired most likely in the classroom. These results hold when entering the learning environment in Model 2. However, time spend on self-study and time spent on studying a second subject increases the performance of students with respect to generic competencies. Paid work, at least when it is related to the study followed also adds to the acquisition. Finally, we find no significant impact of time allocated to extra curricular activities. With respect to time allocated to internships or time spent abroad, we find that graduates only benefit from staying some time abroad. Generally, all results of the time allocation stay strongly robust when in Model 2 the dummies for the learning environments are added, indicating that the time allocation is not a priori endogenous to the learning environment.

Considering finally the impact of other curriculum aspects ${ }^{31}$, we see that, although most of them have a significant and positive impact, in particular an increased emphasis on 'independent learning' increases the student's effectiveness. Moreover, their inclusion sharply reduces the effects of our learning environment variables.

Let us continue the discussion with the results of the level of discipline-specific competencies (see Table 4.3). The setup of the models follows closely the above discussed setup. However, we add the predicted value of generic competencies as explanatory variable. As instrumental variables, we use the dummy for higher educated parents, the age of the students, the dummy for academic secondary schooling and the two dummies indicating the grades with which the students passed their secondary education exams. Hence, these variables of the generic competencies estimation do not turn up in the discipline-specific competencies models. The selection of instruments is based on the findings presented in Table 4.1 and on preliminary results with respect to the level of discipline-specific competencies ${ }^{32}$. Moreover, different tests confirmed the validity of our instruments (see Table 4.2). First, we provide an F-test statistic in order to test the correlation between the instruments and the level of generic competencies acquired. The resulting coefficients are strongly significant and provide a first validation of the used instruments. Second, we tested with a Hausman t-test if OLS and IV coefficients are significantly different from each other. This test is implemented by including the residuals obtained from the regression of generic competencies on the instruments as a regressor in the discipline-specific equation and testing its significance. If it is significant, the null hypotheses (OLS estimate = IV estimate) is rejected. With the exception of Model 3, the tstatistic is significant on a $5 \%$ level validating again our instruments. Finally, we test if the instruments are orthogonal to the error term of the discipline-specific regression. In order to test this, the Sargan miss-specification is implemented. The null hypotheses for valid

31. All of these variables are dummies which are 1 when the respondent indicated that the higher education institute put strong or very strong emphasis on this aspect and 0 otherwise.

32. Data not reported in this paper. 
instruments can clearly not be rejected. Hence, we can conclude that our instruments are strongly valid for our purpose.

Table 4.2

Tests for instrument variables validity

\begin{tabular}{lccccc} 
Test & Model 0 & Model 1a & Model 1b & Model 2 & Model 3 \\
\hline F-test on excluded variables & $37.64^{\star * *}$ & $40.44^{\star * *}$ & $33.87^{\star \star *}$ & $34.64^{\star * *}$ & $33.95^{\star * *}$ \\
Hausman t-test of exogeneity & $-2.009^{* *}$ & $-2.069^{* *}$ & $-2.095^{\star *}$ & $-2.047^{* *}$ & $-1.835^{*}$ \\
Sargant's identification test & 7.87 & 8.04 & 7.93 & 7.67 & 8.75
\end{tabular}

Note: All tests are based on 2SLS regressions

We turn first to the result with respect to our remaining personal characteristic. Similar to our finding with respect to generic competencies, we see that male students perform less effective in the acquisition of discipline-specific competencies than female students. However, the impact is this time clearly smaller and only significant on a $10 \%$ level. Moreover, it looses its significance when other aspects are entered (see Model 1 through Model 3).

Entering in Model 1a the variables representing the different learning environments reveals that the 'PBL with teacher style' is clearly the most effective one. On the other hand, no significant differences are found between the 'PBL without teacher style' and the 'traditional style' or between the 'PBL without teacher style' and the 'school class style'. However, the 'school class style' is slightly more efficient than the 'traditional style'. These findings stay robust when entering in Model 2 the information on the time allocation and in Model 3 the information on additional curriculum aspects. ${ }^{33}$ In other words, our results seem to indicate that there is an important role in the acquisition of discipline-specific competencies laid down for the teacher in transferring information to the students.

Turning to Model $1 \mathrm{~b}$, we see that attending formal education is an effective manner of time allocation. ${ }^{34} 35$ Moreover, the coefficient for the 'required formal education' indicates that the effectiveness of class attention is strongly influenced by the question if the institute one attends the study puts a lot of emphasis on student attendance or not. More precisely, one hour of class attention is approximately twice as effective when the institute puts an

33. In Model 3 , the school-class style gets more efficient on a $10 \%$ significance level than the PBL without teacher style.

34. It is important to note that we are unable to distinguish between the number of hours the student attends class and the number of class hours offered by the higher education institute. Hence, an alternative explanation of this result is that higher education institutes should increase the number of class hours offered.

35. We tested the extent to which the return to formal education is dependent on the amount of selfstudy used as preparation time for the formal education. As an increased amount of formal education might reduce the average time available for preparation, one could expect the return to formal education per hour self-study to be diminishing. However, no such impact was found. 
emphasis on attendance than when the institute does not. Moreover, attending required formal education is more effective as self-study. Neither time allocated to studying a second subject $^{36}$ nor time allocated to extra curricular activities show a significant impact. Finally, we see that time allocated to paid work is not by definition time taken away from the acquisition of discipline-specific competencies, at least not as long as the work is strongly related to the study one follows. The findings with respect to the time allocation variables stay robust when entering in Model 2 the learning environment and in Model 3 additional curriculum aspects. No significant impact is found from variables indicating that the student participated during his study in a short or long internship but a significant negative impact is found in the case that the student spent some time abroad. In other words, and combining this result with the above presented impact of staying abroad on generic competencies, we see that even though students that spent some time abroad increase their level of generic competencies, which by itself helps to increase the effectiveness in the discipline-specific competencies acquisition, end up with a reduced level of discipline-specific competencies compared to students that stayed home.

Concluding our discussion on the findings of Table 4.3, we have a short look at the additional curriculum aspects entered in Model 3. The results indicate that in particular attention on 'facts and practical knowledge' and attention on 'theories and concepts' have a high impact.

Before presenting some concluding remarks with respect to these empirical results, some important side marks are discussed.

First, we tested the robustness of the results by applying a Cobb-Douglas functional form instead of the linear functional form underlying the results presented in Table 4.1 and Table 4.3. Moreover, we tested the extent to which our approach to normalize the dependent variables influences the story and finally, we also compared the stochastic frontier approach with simple OLS estimations. All tests ${ }^{37}$ indicate that our main results are robust to changes in the functional form applied to.

Second, the stochastic frontier approach allows us to examine the decomposition of the variance into its two parts: $v_{i}$, the random variable assumed to be iid. $\mathrm{N}\left(0, \sigma_{v}{ }^{2}\right)$ and $\mu_{i}$, the non-negative random variable accounting for technical inefficiency. According to Greene (2000), the variance of the composite error $\varepsilon_{i}$ is given by

(9) $\sigma_{\varepsilon_{i}}^{2}=\left[(1-2 / \pi) * \sigma_{\mu_{i}}^{2}\right]+\sigma_{v_{i}}^{2}$

36. We would like to remember the reader that we measure the discipline-specific competencies of the main subject. Hence, this result does not indicate that time allocated to a second subject is not useful in acquiring discipline-specific competencies of the second subject.

37. Data not shown in this paper. 
Table 4.3

The impact on discipline-specific competencies

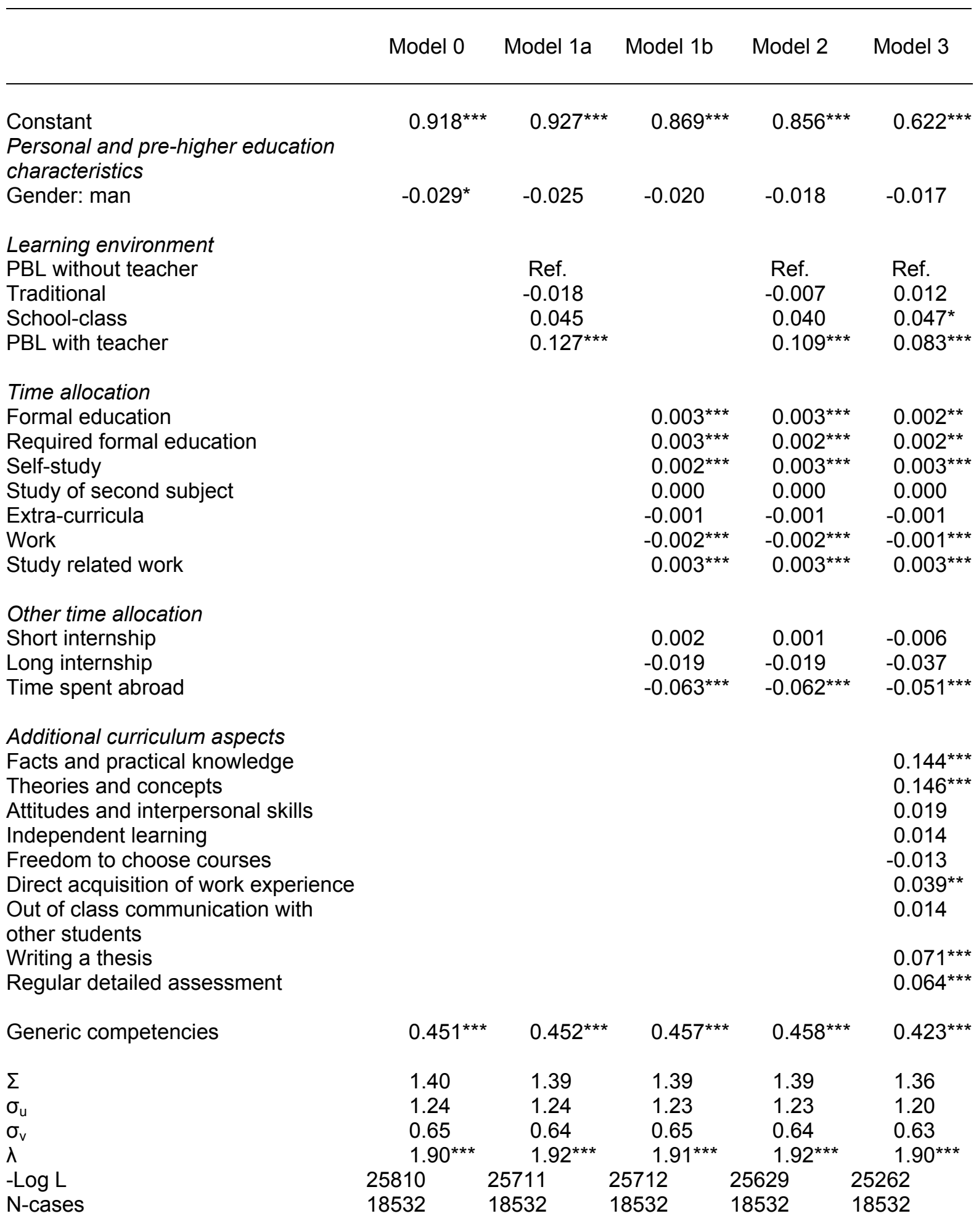

Note 1: All models further include dummies for the nine countries, dummies for the different higher education institutions inside a country and dummies for seven educational programs. Note 2: *** significant at a $1 \%$ level, ${ }^{* *}$ significant at a $5 \%$ level, ${ }^{*}$ significant at a $10 \%$ level 
In case of the discipline-specific competencies estimation (Model 3 ) around $57 \%$ and in case of the generic competencies estimation (Model 3 ) around $30 \%$ of the total variance of $\varepsilon_{i}$ is accounted for by the variance of $\mu_{i}$, and hence can be attributed to technical inefficiency ${ }^{38}$. As in the case of generic competencies more than two third of the variance has to be attributed to unexplained variance, one might wonder if using a stochastic production frontier, in contrast to a simple linear regression, adds value to the empirical estimation. To address this, we have a look at the $\lambda$ reported in Table 4.1 and Table 4.3. $\lambda$ is a measure of the relative weight of the inefficiency in the empirical estimations:

(10) $\lambda=\sigma_{\mu_{i}}^{2} / \sigma_{v_{i}}^{2}$

In all our estimations, the $\lambda$ parameter is highly significant different from zero ${ }^{39}$, indicating that the use of the frontier production functions is appropriate.

Let us return to our initial dilemma between the acquisition of generic competencies and the acquisition of discipline-specific competencies. We have reached a stage where we are able to address the question if a higher education programme confronted with a change in the relative weight attached to one of the two competencies in the labour market is able to react on it without having to accept a trade-off between the two competencies types. To simplify the main conclusions, Table 4.4 summarises qualitatively the change a standard student will be confronted with through a change in the learning environment (according to Model 3 ).

Table 4.4

A change in the learning environment

\begin{tabular}{|c|c|c|c|c|c|c|c|c|}
\hline \multirow[t]{2}{*}{$\begin{array}{l}\text { New Style } \\
\text { Old style }\end{array}$} & \multicolumn{2}{|c|}{ Traditional } & \multicolumn{2}{|r|}{ School-class } & \multicolumn{2}{|r|}{$\begin{array}{l}\text { PBL without } \\
\text { teacher }\end{array}$} & \multicolumn{2}{|r|}{$\begin{array}{l}\text { PBL with } \\
\text { teacher }\end{array}$} \\
\hline & G & DS & G & DS & $\mathrm{G}$ & DS & $\mathrm{G}$ & DS \\
\hline Traditional & & & 0 & + & + & 0 & + & + \\
\hline School-class & 0 & - & & & + & $(-)$ & + & 0 \\
\hline PBL without teacher & - & 0 & - & $(+)$ & & & 0 & + \\
\hline PBL with teacher & - & - & - & 0 & 0 & - & & \\
\hline
\end{tabular}

Note: First sign indicates change in generic competencies; Second sign indicates change in discipline-specific competencies. () indicates that change is significant only on a $10 \%$ level.

The results summarized in Table 4.4 show that for both more conventional styles, namely the 'traditional style' and the 'school class style', more effective alternatives are available. In the former case, this will be the 'PBL without teacher style' or the 'PBL with teacher style'

38. These figures differ not significantly between the four models estimated.

39. In case of an ordinary linear regression with a normal distributed error term.$\lambda$ is zero. 
(although this would imply to change both didactic instruments discussed here). In the latter case, implementing the 'PBL with teacher style' would provide a pareto improvement. In case of the 'PBL without teacher style' those responsible might consider strengthening the role of the teacher in transferring information to the students. However, one has to be careful to keep the active discoverer student and not reaching the 'school class style'.

Considering the impact of the time allocation over different study activities, Table 4.5 gives a qualitative summary based on the results of model 3 .

Table 4.5

Impact of student time allocation on competencies

Formal education

Required formal education

Self-study

Study of second subject

Extra curricula activities

Work

Study related work

$\begin{array}{lc}+ & (-) \\ + & 0 \\ + & + \\ 0 & + \\ 0 & 0 \\ - & 0 \\ + & +\end{array}$

Note: () indicates that the change is only significant on a $10 \%$ level

Considering solely marginal changes in the time allocated to a particular study activity and hence allowing an increase in time in one activity without having to reduce the time spent on another activity, we can conclude the following: Whereas increasing the time spent on formal education that is not required yields a move along the initial production possibility frontier towards more discipline-specific competencies and less generic competencies, an increase in time spent on required formal education allows to move out to a higher production possibility frontier. Such an outward move is also possible through more time allocated to self-study, study of a second subject (however in this case only the generic competencies level increases) and through allocating more time to study related work. Finally, no change in the location on the production possibility frontier takes place in case the student allocates more time to extra curricula activities but, the student moves towards a lower production possibility frontier if increasing the time spent on work that is not related to the study.

\section{Conclusion}

The objective of this paper was to analyze the impact of the learning environment and the student's time allocation on the acquisition of generic and discipline-specific competencies. The interest in this topic is based on the finding that in the last decades there seems to be an increased emphasis on generic competencies in the labor market. Moreover, criticism on traditional teaching styles in higher education has led to a widespread establishment of activating learning methods. These methods are the visible surface of a much deeper paradigm shift that is taking place in higher education: A change from higher education 
institutes as place that exists to provide instruction to a higher education institute that exists to produce learning. The idea behind activating learning environments, such as problembased learning, is that they stimulate the active discoverer in the student and promotes the acquisition of generic competencies, such as gathering information or problem-solving abilities.

Considering these newer didactic methods, the question arises if they simply trade the acquisition of discipline-specific competencies for the acquisition of generic competencies or allow to provide a win-win situation: higher education graduates are able to acquire both types of competencies on a higher level. To address this question, considering the student's time allocation over different modes of study, which might partially be endogenous to the didactic method, needs to be addressed as well.

We started by regarding higher education as a production process in which a variety of inputs are used to determine a multidimensional output. The multidimensionality addressed referred to the distinction between generic and discipline-specific competencies. Whereas the latter combined knowledge on field-specific theories and methodologies, the former was defined as a group of abilities providing a strong basis for further learning and for flexibility in the labor market (e.g. problem-solving abilities, knowing how to learn, analytical competencies). We then analyzed to what extent the learning environment and the student's time allocation added to the acquisition of these two types of competencies.

Concerning the learning environment, we found that using activating learning methods increases the performance of students not only with respect to the acquisition of generic competencies but as well with respect to the acquisition of discipline-specific competencies. However, for the latter effect to hold, the role of the teacher inside an activating learning environment should not be underestimated. Teachers combining activating learning methods with a strong role in knowledge transfer for themselves allow students to perform better than when just controlling the discussion process of the workgroups in a problem- or projectbased learning method environment. Hence, applying a mix between the teacher as central source of information and activating learning methods provides a win-win situation.

Concerning the student time allocation, our results show that attending classes, in particular when the higher education institute places a strong emphasis on class attention, self-study, as well as work that is strongly related to the field of study helps to increase the effectiveness with which discipline-specific competencies are acquired. Whereas the latter two effects also increase the effectiveness with which generic competencies are acquired, we find that formal education seems to be harmful for it.

Even though our analyzes established that activating learning environments, such as problem- or project-based learning, enhance the effectiveness with which generic competencies are acquired without harming the acquisition of discipline-specific competencies, we have to be cautious in connecting direct policy advises to these results. As a matter of fact, we were unable to analyze the cost side of implementing activating 
learning environments. Activating learning environments imply generally smaller class sizes and might force university staff to increase their time devoted to teaching. Hence, to complete the picture, analyses on financial costs or reduced research output due to the implementation of activating learning environments is needed in the future. 


\section{References}

Aigner, D., Lovell, K., Schmidt, P., (1977), Formulation and Estimation of Stochastic Frontier Production Models, Journal of Econometrics, 2, 365-372.

Albeda, W., (1998), The Need for Labour Market Transparency in a Changing Economy, in: Heijke, H., Borghans, L., (eds), Towards a Transparent Labour Market for Educational Decisions, Ashgate, Aldershot/Brookfield (USA)/Singapore/Sydney, pp. xiii-xviii.

Barr, R., Tagg, J., (1995), From Teaching to Learning - A New Paradigm for Undergraduate Education, Change, November/December, pp. 13-25.

Battese G.E. and Coelli T.J. (1988), Prediction of Firm- Level Technical Efficiencies With a Generalised Frontier Production Function and Panel Data, Journal of Econometrics, 38, pp. 387-399

Becker, G. (1964), Human capital, University of Chicago Press: Chicago.

Biggs, J., 2003, Teaching for quality learning at university: what the student does, $2^{\text {nd }}$ edition, Open University Press: Berkshire.

Bloom, B.S., 1956, Taxonomy of educational objectives: The classification of educational goals. Handbook 1: Cognitive domain, New York: McKay.

Bossche van den, P., Segers, M., Gijbels, D. \& Dochy, F. (2001). Effecten van het probleemgestuurd economisch curriculum. Tijdschrift voor Hoger Onderwijs, 19, (4), pp. 254-277.

Bowden, J., Masters, G.N., (1993), Implications for Higher Education of a CompetencyBased Approach to Education and Training, AGPS, Canberra.

Bowden, J., Marton, F. (1998), The University of Learning, Beyond Quality and Competence, Kogan Page, London.

Bratti, M., Staffolani, S., 2002, Student time allocation and educational production functions, HEW 0207001, Economics Working Paper Archive at WUSTL, Washington University, Washington.

Chan, K.C., Shum, C., Wright, D.J. (1997) Class Attendance and Student Performance in Principles of Finance, Financial Practice and Education, 7(2), pp. 58-65.

Corte de, E. (1990). Toward powerful learning environments for the acquisition of Problem solving skills. European journal of psychology of education, 5, (1), pp. 5-19.

Devadoss, S. and Foltz, J. (1996), Evaluation of Factors Influencing Student Class Attendance and Performance, American Journal of Agricultural Economics, 78(3), pp. 499-507.

Dewey, J., (1916), Democracy and Education, The Macmillian Company.

Dochy, F., Segers, M., van den Bossche, P. and Gijbels, D. (2003). Effects of problembased learning: a meta analysis. Learning and Instruction, 13, pp. 533-568.

Dolton, P., Marcenaro, O.D., Navarro, L.(2001) The Effective Use of Student Time: A Stochastic Frontier Production Function Case Study, Center for the Economics of Education, London School of Economics,London.

Durden, G. C. and Ellis, L. V. (1995) 'The Effects of Attendance on Student Learning in Principles of Economics', American Eonomic Review, 85(2), pp. 343-346.

Ennis, C., 1987, A taxonomy of critical thinking dispositions and abilities, in Baron, J.B., Sternberg, R.J. (eds.) Teaching thinking skills, New York: Freeman, pp. 9-26. 
Everwijn, S.E.M. (1999). Het hoe, wat en waarom van competentiegericht onderwijs. In: Schlusmans, K., Slotman, R., Nagtegaal, C. and Kinkhorst, G. (eds) Competentiegerichte leeromgevingen. Utrecht: Uitgeverij Lemma.

Gerritsen, R. (1999), Do students study more thoroughly within a problem-based learning course, in: J. Hommes, et al. (eds), Educational Innovation in Economics and Business IV: Learning in a Changing Environment, Kluwer Academic Publishers, Dordrecht/Boston/London, pp. 127-141.

Greene, W.H., (2000) Econometric Analysis, 4th ed. Prentice-Hall, New Jersey.

Hanushek, E., 2002, The Failure of Input-based Schooling Policies, NBER Working Papers 9040, National Bureau of Economic Research, Inc.

Heijke, H., Meng, C., Ramaekers, G., (2003), An investigation into the the role of human capital competencies and their pay-off, International Journal of Manpower, Vol. 24, 7, pp. 750-773.

Heijke, H., Meng, C., Ris, C., (2003), Fitting to the job: the role of generic and vocational competencies in adjustment and performance, Labour Economics, 10 (2003), 215-229.

Heijke, H., Meng, C, (forthcoming), The effects of higher education programme characteristics on allocation and performance of the graduates, ROA Research Memorandum, University of Maastricht.

Juster, F. and Stafford, F., (1991), The Allocation of Time: Empirical Findings, Behavioral Models, and Problems of Measurement, Journal of Economic Literature, vol. XXIX (June 1991), pp. 471-522.

Juster, F. and Stafford, F., (1986), Response Errors in the Measurement of Time Use, Journal of the American Statistical Association, 81 (394), pp. 390-402.

Macan, T., Shahani, C., Dipboye, R.L. Phillips, A., (1990), College students'time management: Correlations with academic performance and stress. Journal of Educational Psychology, 82(4), pp. 760-768.

McCall, M.W., Lombardo, M.M. \& Morrison, A.M. (1988), The Lessons of Experience. How Successful Executives Develop on the Job, The Free Press, New York.

Meeusen, W., Broeck, van den J., (1977), Efficiency Estimation from Cobb-Douglas Production Functions with Composed Error, International Economic Reviwe, 18, pp. 435444.

Milter, R.G., Stinsons, J.E. (1995), Education leaders for the new competitive environment, in Gijselaers, W.H.,Tempelaar, D.T., Keizer, P.K., Blommaert, J.M., Bernard, E.M., Kasper, H. (eds), Educational Innovation in Economics and Business Administration: The Case of Problem-Based Learning, Kluwer Academic Publishers, Dordrecht, pp. 30-38..

Mulligan, C., Schneider, B. and Wolfe, R., (2000), Time Use and Population Representation in the Sloan Study of Adolescents, NBER Technical Working Paper 265.

Norman, G.R. \& Schmidt, H.G. (2000), Effectiveness of problem based learning curricula: theory, practice and paper darts, Medical Education, 34 (9), 721-728.

Nunnually, J.C., 1978, Psychometric Theory, 2nd ed. McGraw-Hill, New York.

Prosser, M., Trigwell, K., 1999, Understanding learning and teaching: the experience in higher education, SRHE and Open University Press: Buckingham.

Ramsden, P., 2003, Learning to teach in higher education, RoutledgeFalmer: London.

Romer, D. (1993), Do Students Go to Class? Should They?, Journal of Economic Perspectives, 7(3), pp. 167-174. 
Rosen, S. (1983), Specialization and human capital, Journal of Labor Economics, 1(1), pp. 43-49.

Schmidt, R. M. (1983), Who Maximizes What? A Study in Student Time Allocation, American Economic Review, 73(2), pp. 23-28.

Schmidt, H. \& Bouhuijs, P. (1985), Onderwijs in taakgerichte groepen, Utrecht and Antwerp, Spectrum, Aula Books

Stepenson, J.,(1992), Capability and quality in higher education in J. Stephenson and S. Weil (eds), Quality in Earning: A capability Approach in Higher Education, Kogan Page, London, pp. 1-9.

Sunday Times, 14.09.2003, The Sunday Times University League Table.

Teichler, U., (1999) Higher education policy and the world of work: changing conditions and challenges, Higher Education Policy, 12 (1999), pp. 285-312.

Vaatstra, R., de Vries, R., (2003), De relatie tussen onderwijsvorm, competenties en arbeidsmarkt, Tijdschrift voor Hoger Onderwijs, 21, (1), pp. 144-158.

Weinert, F. E., 2001, Concept of Competence: A Conceptual Clarification, in: Rychen, D. S., Salganik, L. H., Defining and selecting key competencies, Göttingen: Hogrefe \& Huber Publishers.

Woerden van, W. (1997). De ontwikkeling van activerend onderwijs: probleemgestuurd leren en projectonderwijs. In: Ten Dam, G.T.M., Van Hout, J.F.M.J., Terlouw, C. and Willems, J. (eds). Onderwijskunde Hoger Onderwijs. Assen: Van Gorcum, pp. 186-213. 


\section{Appendices}

\section{Appendix A: Characteristics of Data}

Table A.1

$\%$ of graduates per field of study and $\mathrm{N}$-cases

\begin{tabular}{|c|c|c|c|c|c|c|c|c|c|}
\hline & & $A H$ & SS & $B U$ & $L A$ & $N S$ & $E N$ & \multicolumn{2}{|c|}{ HE N-cases } \\
\hline Italy & U & 17.7 & 12.1 & 21.7 & 7.4 & 13.3 & 20.2 & 7.7 & 1252 \\
\hline Spain & $U$ & 15.6 & 12.0 & 13.1 & 4.3 & 12.6 & 25.1 & 17.3 & 1568 \\
\hline France & U & 19.1 & 28.3 & 9.7 & 13.5 & 23.3 & 6.1 & ---- & 1056 \\
\hline France & GE & ---- & ---- & 49.0 & ---- & 29.3 & 21.2 & ---- & 547 \\
\hline Austria & U & 21.4 & 9.3 & 18.2 & 11.1 & 9.3 & 19.3 & 11.5 & 1758 \\
\hline Germany & U & 21.0 & 6.9 & 16.5 & 5.1 & 19.1 & 21.1 & 10.4 & 1937 \\
\hline Germany & $\mathrm{FH}$ & 4.7 & ---- & 37.9 & 6.2 & 1.9 & 42.6 & 6.4 & 808 \\
\hline Netherlands & $U$ & 16.5 & 19.6 & 15.4 & 13.4 & 9.6 & 11.1 & 14.4 & 1077 \\
\hline Netherlands & $\mathrm{HBO}$ & 21.2 & 2.7 & 30.4 & ---- & 4.8 & 18.7 & 22.2 & 1544 \\
\hline United Kingdom & OU & 33.5 & 13.1 & 9.7 & 4.6 & 19.4 & 12.3 & 7.3 & 1363 \\
\hline United Kingdom & NU & 31.7 & 11.1 & 17.5 & 3.1 & 11.7 & 11.2 & 13.7 & 1136 \\
\hline Finland & U & 28.4 & 10.8 & 12.3 & 3.3 & 13.0 & 21.9 & 10.3 & 2069 \\
\hline Norway & U & 14.1 & 17.8 & 7.6 & 12.7 & 18.9 & 19.1 & 9.7 & 1306 \\
\hline Norway & UC & 20.7 & 3.2 & 4.9 & ---- & 1.8 & 21.1 & 48.4 & 1424 \\
\hline
\end{tabular}




\section{Appendix B: Definitions of variables used}

\section{Dependent Variables:}

Discipline-specific competencies

Generic competencies

\section{Independent variables}

Higher educated parents

Gender: man

Age

Academic pre-education

Medium (High) secondary grades

PBL without teacher

Traditional

School class

PBL with teacher

Formal education

Required formal education

Self-study

Study of second subject

Extra-curricula

Work

Study related work

Facts and practical knowledge

Theories and concepts

Attitudes and interpersonal skills

Independent learning

Freedom to choose courses
Normalized average of items

Normalized average of items

Dummy if mother and/or father has higher education diploma

Dummy if respondent is male

Age in years at time of survey

Dummy if respondent followed before HE an academic secondary Education

Dummy if respondent graduated from secondary school with medium (high) average grades

Dummy if study took place in PBL without teacher learning environment

Dummy if study took place in traditional learning environment

Dummy if study took place in school class learning environment

Dummy if study took place in PBL with teacher learning environment

Hours weekly spent on attending classes/lectures/meetings Hours weekly spent on attending classes/lectures/meetings if attendance was required Hours weekly spent on self-study Hours weekly spent on studying a second subject Hours weekly spent on extra-curricula activities Hours weekly spent on paid employment Hours weekly spent on paid employment if work was related to Study Dummy if HE institute put high or very high emphasize on this aspect

Dummy if HE institute put high or very high emphasize on this aspect

Dummy if HE institute put high or very high emphasize on this aspect

Dummy if HE institute put high or very high emphasize on this aspect

Dummy if HE institute put high or very high emphasize on this aspect 
Direct acquisition of work experience

Out of class communication with other students

Writing a thesis

Regular detailed assessment
Dummy if HE institute put high or very high emphasize on this aspect

Dummy if HE institute put high or very high emphasize on this aspect

Dummy if HE institute put high or very high emphasize on this aspect

Dummy if HE institute put high or very high emphasize on this aspect 


\section{Appendix C: University versus higher vocational education}

This appendix reports on the results of Model 2 for two separate types of higher education graduates: University graduates and higher vocational education graduates.

Table C.1

The impact on competencies: University versus Higher vocational education

\begin{tabular}{|c|c|c|c|c|}
\hline \multirow{4}{*}{$\begin{array}{l}\text { Constant } \\
\text { Personal and pre-higher education } \\
\text { characteristics }\end{array}$} & \multicolumn{2}{|c|}{ University type } & \multicolumn{2}{|c|}{ Higher vocational type } \\
\hline & Generic & $\begin{array}{l}\text { Discipline- } \\
\text { specific }\end{array}$ & Generic & $\begin{array}{l}\text { Discipline- } \\
\text { specific }\end{array}$ \\
\hline & $0.433^{* * *}$ & $0.849^{* * *}$ & $0.442^{* *}$ & $0.840^{* * *}$ \\
\hline & & & & \\
\hline Higher educated parents & $0.031^{*}$ & & -0.023 & \\
\hline Gender: man & $-0.092^{* * *}$ & -0.020 & -0.051 & -0.007 \\
\hline Age & $0.010^{* * *}$ & & $0.007^{* *}$ & \\
\hline Academic pre-education & $0.110^{* * *}$ & & $0.093^{* *}$ & \\
\hline Low secondary grades & Ref. & & Ref. & \\
\hline Medium secondary grades & $0.081^{* * *}$ & & $0.119^{* * *}$ & \\
\hline High secondary grades & $0.240^{* * *}$ & & $0.290^{* * *}$ & \\
\hline \multicolumn{5}{|l|}{ Learning environment } \\
\hline PBL without teacher & Ref. & Ref. & Ref. & Ref. \\
\hline Traditional & $-0.337^{* * *}$ & -0.005 & $-0.282^{* * *}$ & 0.026 \\
\hline School-class & $-0.335^{\star * *}$ & 0.043 & $-0.283^{* * *}$ & 0.070 \\
\hline PBL with teacher & 0.023 & $0.118^{* * *}$ & $0.132^{* *}$ & $0.090^{*}$ \\
\hline \multicolumn{5}{|l|}{ Time allocation } \\
\hline Formal education & $-0.002^{* *}$ & $0.003^{* * *}$ & -0.003 & 0.002 \\
\hline Required formal education & $0.002^{* *}$ & $0.002^{* * *}$ & 0.002 & 0.002 \\
\hline Self-study & $0.006^{* * *}$ & $0.003^{* * *}$ & $0.007^{* * *}$ & 0.001 \\
\hline Study of second subject & $0.005^{* *}$ & 0.001 & $0.011^{* *}$ & -0.005 \\
\hline Extra-curricula & 0.001 & -0.001 & -0.002 & -0.004 \\
\hline Work & $-0.001^{*}$ & $-0.002^{* * *}$ & 0.002 & $-0.002^{* *}$ \\
\hline Study related work & $0.003^{* * *}$ & $0.003^{* * *}$ & 0.002 & 0.002 \\
\hline \multicolumn{5}{|l|}{ Other time allocation } \\
\hline Short internship & -0.023 & -0.016 & -0.048 & 0.072 \\
\hline Long internship & -0.032 & -0.033 & 0.006 & 0.011 \\
\hline Time spent abroad & 0.052 & $-0.059^{* * *}$ & 0.055 & -0.071 \\
\hline$\Sigma$ & 1.25 & 1.39 & 1.24 & 1.37 \\
\hline$\sigma_{\mathrm{u}}$ & 0.97 & 1.24 & 0.89 & 1.20 \\
\hline$\sigma_{v}$ & 0.64 & 0.63 & 0.86 & 0.66 \\
\hline$\lambda$ & $1.21^{* * *}$ & $1.39^{* * *}$ & $1.04^{* * *}$ & $1.81^{* * *}$ \\
\hline$-\log L$ & 20784 & 20477 & 5320 & 5149 \\
\hline $\mathrm{N}$-cases & 14820 & 14820 & 3713 & 3713 \\
\hline
\end{tabular}

Note: University type: this estimation includes the university graduates in all nine countries; Higher vocational type: this estimation includes graduates from HBO, Fachhochschulen and university colleges (Norway). All models further include dummies for the countries, and dummies for seven educational programs. ${ }^{* * *}$ significant at a $1 \%$ level, ${ }^{* *}$ significant at a $5 \%$ level, ${ }^{*}$ significant at $10 \%$ level. 
Considering the learning environment, we see that the results are strongly comparable between the two types of higher education. Considering the time allocation, we find that for graduates of higher vocational education the significance of the coefficients is clearly smaller. This finding is related to the fact that higher vocational education students generally spoken possess less freedom in their time allocation than university students. 